\title{
Symptoms and diagnostic delay in patients with carcinoma of oesophagus and gastric cardia: a retrospective study of 225 patients
}

\author{
K. OJala* \\ M.D. \\ K. JOKINEN* \\ M.D. \\ M. SORRI* \\ M.D. \\ M. I. Kairaluoma $\dagger$ \\ M.D. \\ Departments of * Otolaryngology and $\uparrow$ Surgery, University of Oulu, Oulu, Finland
}

\begin{abstract}
Summary
A retrospective review of 225 patients was made with regard to the symptoms of carcinoma of the oesophagus and gastric cardia, and the duration of the symptoms before medical attention was sought and before the establishment of the diagnosis. The age of the patients was 37-84 (mean 62.5) years (139 male, 86 fenale). The most common symptoms were dysphagia $(93 \%)$, loss of weight $(46 \%)$, vomiting (33\%), gastric pain (25\%) and thoracic pain (21\%).

The average duration of the symptoms before the establishment of the diagnosis was $4 \cdot 1$ months in carcinoma of the oesophagus and 4.3 months in carcinoma of the gastric cardia. The patients with oesophageal disease had sought medical attention on average 5 weeks earlier than those with gastric disease. The role of the physician who initially examines the patient is decisive for early diagnosis.
\end{abstract}

\section{Introduction}

Carcinoma of the oesophagus is more common in Finland than in many countries, the incidence of the disease being about twice that of other Scandinavian countries (Appelqvist, 1972). It has been shown to be somewhat more common in men (Segi, Kurihama and Matsyama, 1969), but according to Appelqvist (1972) the disease in south and southwestern Finland is more common among women. Appelqvist also reported that it occurs on the whole more often in southern Finland than in northern Finland and that about $10 \%$ of the patients had a factor commonly recognized as predisposing to this disease (lye-stricture, benign ulcer).

The symptoms of cancer of the oesophagus and gastric cardia are often minor for a long time, which thus makes the early establishment of the diagnosis difficult. Often the patient seeks medical attention only after several months, and occasionally more than a year after the onset of symptoms (Appelqvist,
1972; Inberg et al., 1974). If this initial contact with a physician does not result in further studies which can establish the diagnosis, there may be an additional delay of several months, or even a year, before the diagnosis is established (Hegeman and Geldmacher, 1962; Appelqvist, 1972).

The most common symptoms of the disease are dysphagia, loss of weight, pains in the chest, stomach, throat and at times, in the back (Dietrich et al., 1964; Appelqvist, 1972; Inberg et al., 1974). Watson (1933), Stranahan, Gobbel and Olsson (1954), Le Roux (1961) and Appelqvist (1972) have reported dysphagia to be the most common initial symptom, occurring in $59-73 \%$ of their patients as the initial symptom. Other symptoms, especially in tumours of the upper part of the oesophagus, are cough, hoarseness, and a sensation of a lump in the throat or oesophagus. Other common symptoms are anorexia, hiccups and dyspepsia, as well as anaemia, haemoptysis and bloody stools in tumours of the lower part of the oesophagus and gastric cardia (Stranahan et al., 1954; Dietrich et al., 1964; Appelqvist, 1972).

When a patient complains of such symptoms the possibility of malignancy must always be kept in mind and studies to determine the cause of the symptoms must be initiated without delay. Radiological examinations inconvenience the patient only slightly and are thus valuable diagnostic tools before endoscopy (Dietrich et al., 1964) although false-negative results can occur in as many as $30 \%$ of patients (Appelqvist, 1972; Borgeskov, Egedorf and KruseBlinkenberg, 1976). The diagnostic reliability of endoscopy in patients with carcinoma of the oesophagus is good (Appelqvist, 1972; Borgeskov et al., 1976). Diagnostic difficulties occurring both in conjunction with endoscopy and X-ray examinations are more common in carcinoma of the gastric cardia (Appelqvist, 1972). 
TABLE 1. Incidence of symptoms in 225 patients with carcinoma of oesophagus or gastric cardia

\begin{tabular}{|c|c|c|c|c|c|c|c|c|c|c|}
\hline & \multicolumn{2}{|c|}{$\begin{array}{l}\text { Upper } \\
\text { third } \\
(n=9)\end{array}$} & \multicolumn{2}{|c|}{$\begin{array}{c}\text { Middle } \\
\text { third } \\
(n=68)\end{array}$} & \multicolumn{2}{|c|}{$\begin{array}{c}\text { Lower } \\
\text { third } \\
(\mathrm{n}=61)\end{array}$} & \multicolumn{2}{|c|}{$\begin{array}{l}\text { Gastric } \\
\text { cardia } \\
(n=81)\end{array}$} & \multirow{2}{*}{$\begin{array}{c}\text { Total } \\
\text { no. }\end{array}$} & \multirow{2}{*}{$\begin{array}{l}\% \text { of all } \\
\text { patients }\end{array}$} \\
\hline & No. & $\%$ & No. & $\%$ & No. & $\%$ & No. & $\%$ & & \\
\hline Dysphagia & 8 & 89 & 66 & 97 & 58 & 95 & 77 & 89 & 209 & 93 \\
\hline Weight loss & 5 & 56 & 20 & 29 & 32 & 52 & 47 & 54 & 104 & 46 \\
\hline Vomiting & 0 & - & 7 & 10 & 28 & 46 & 39 & 45 & 74 & 33 \\
\hline Gastric pain & 0 & - & 7 & 10 & 20 & 33 & 29 & 33 & 56 & 25 \\
\hline Thoracic pain & 1 & 11 & 11 & 16 & 14 & 23 & 21 & 24 & 47 & 21 \\
\hline Anorexia & 0 & - & 4 & 6 & 4 & 7 & 8 & 9 & 16 & 7 \\
\hline Haematemesis or melaena & 0 & - & 2 & 3 & 4 & 7 & 7 & 8 & 13 & 6 \\
\hline Belching, hiccups, dyspepsia & 0 & - & 1 & 1 & 5 & 8 & 4 & 5 & 10 & 4 \\
\hline Pharyngeal pain & 2 & 22 & 4 & 6 & 3 & 5 & 0 & - & 9 & 4 \\
\hline Sensation of a lump & 3 & 33 & 3 & 4 & 0 & - & 0 & - & 6 & 3 \\
\hline Anaemia & 0 & - & 0 & - & 0 & - & 6 & 7 & 6 & 3 \\
\hline Cough, hoarseness & 2 & 22 & 2 & 3 & 1 & 2 & 0 & - & 5 & 2 \\
\hline Others & 2 & 22 & 8 & 12 & 3 & 5 & 7 & 8 & 20 & 9 \\
\hline
\end{tabular}

\section{Materials and methods}

Patients treated at the University of Oulu Central Hospital, over the period 1964-77, for carcinoma of the oesophagus and carcinoma of the gastric cardia were reviewed retrospectively in regards to the symptoms, their duration before seeking medical attention and before the establishment of the diagnosis, and as to which were the examinations which initially revealed the correct diagnosis.

The study was made up of 225 patients ( 139 male, 86 female). The patients' age at the time of diagnosis varied from 37-84 (mean 62.5) years. Clinical examination, routine laboratory tests, barium swallow $\mathrm{X}$-ray and endoscopy were performed on all of the patients. All diagnoses were verified histologically, either on the basis of biopsies taken upon endoscopy or from specimens obtained at surgery. The histological groupings were as follows: $90 \%(124 / 138)$ of the tumours of the oesophagus were epidermoid carcinomas, $9 \%(12 / 138)$ adenocarcinomas and $1 \%$ $(2 / 138)$ were unclassified carcinomas. $94 \%(82 / 87)$ of the tumours of the gastric cardia were adenocarcinomas and $6 \%(5 / 87)$ were unclassified carcinomas. Sixty-one per cent. (138/225) of all the tumours were located in the oesophagus and $39 \%$ $(87 / 225)$ were located in the gastric cardia.

Of the X-ray contrast examinations, $24 \%$ had been performed initially in examination centres outside our hospital, but only $8 \%$ of the re-examinations were performed elsewhere. Oesophagoscopies were performed in our hospital.

The operability of the whole material was $39 \%$ (32\% of the patients with oesophageal carcinoma and $49 \%$ of patients with carcinoma of the gastric cardia were operated on).

The results were analysed statistically at the Computer Centre of the University of Oulu using the $\chi^{2}$ test for grouped distributions.

\section{Results}

The most common symptoms were dysphagia (obstruction or pain upon swallowing and/or regurgitation; $93 \%)$, weight loss $(46 \%)$, vomiting $(33 \%)$, gastric pain $(25 \%)$, thoracic pain $(21 \%)$, anorexia $(7 \%)$ and symptoms of gastrointestinal bleeding (9\%; Table 1). Respiratory symptoms (cough and hoarseness) also occurred mainly with tumours of the upper oesophagus. Gastrointestinal bleeding and anaemia were found in tumours of the lower oesophagus and gastric cardia. Other symptoms, such as poor general condition, infections, backache, or pain in the lower abdomen occurred in $9 \%$ of patients. The most striking feature is the large percentage of patients with dysphagia as the chief symptom, regardless of the location of the tumour. Dysphagia was the initial symptom in $82 \%$ of our patients.

The duration of symptoms in carcinoma of the upper third of the oesophagus before diagnosis was an average of 3.9 months. The corresponding figure was 3.7 months for carcinoma of the middle third and 4.5 months for the lower third, and 4.3 months for carcinoma of the gastric cardia (Table 2). A significantly greater proportion of patients with carcinoma of the middle third of the oesophagus were diagnosed within 3 months of the initiation of symptoms $(64 \%)$ than patients with carcinoma of the cardia $(43 \% ; P<0.05)$. Likewise, a significantly greater portion of the patients with carcinoma of the gastric cardia (30\%) than those with carcinoma of the middle third of the oesophagus $(23 \% ; P<0.05)$ were diagnosed 3-6 months after the onset of symptoms. There were no other significant differences between the various groups in regards to the amount of time required before the establishment of the diagnosis. The frequency of early diagnosis declined along with the descending location of the carcinoma. 
TABLE 2. Duration before diagnosis of the symptoms of 225 patients with the carcinoma of oesophagus or gastric cardia

\begin{tabular}{lrrrrrrrrrr}
\hline & \multicolumn{10}{c}{ Time (months) } \\
\cline { 2 - 10 } $\begin{array}{l}\text { Location of } \\
\text { carcinoma }\end{array}$ & \multicolumn{1}{c}{$0-1$} & \multicolumn{1}{c}{${ }^{1-3}$} & \multicolumn{1}{c}{$3-6$} & \multicolumn{2}{c}{$6-12$} & \multicolumn{2}{c}{ over 12 } \\
\hline Upper third & 1 & 11 & 5 & 56 & 1 & 11 & 2 & 22 & 0 & - \\
Middle third & 14 & 21 & 29 & 43 & 16 & 23 & 5 & 7 & 4 & 6 \\
Lower third & 9 & 15 & 25 & 41 & 16 & 26 & 6 & 10 & 5 & 8 \\
Gastric cardia & 8 & 9 & 29 & 34 & 35 & 40 & 12 & 14 & 3 & 3 \\
Total & 32 & 14 & 88 & 39 & 68 & 30 & 25 & 11 & 12 & 5 \\
\hline
\end{tabular}

Medical attention was sought by $17 \%$ of patients within a month of the onset of symptoms, by $60 \%$ within 3 months, by $88 \%$ within 6 months and by $96 \%$ within 12 months. Only $4 \%$ of the patients sought medical attention after more than a year's duration of the symptoms.

The average delay between the time of the initial contact with a physician and the time of diagnosis was 5 weeks ( 1 day- 5 months), the diagnosis, thus, usually being achieved quite rapidly. The establishment of the diagnosis required an average of 4 weeks from the time of the initial contact in tumours of the upper and middle thirds of the oesophagus, 5 weeks in tumours of the lower third of the oesophagus and 5.5 weeks in carcinoma of the gastric cardia. Considerable delay was present ( 2.5 months) in one case of a tumour of the cervical oesophagus, and in five cases of carcinoma of the gastric cardia (3-5 months).

In $19 \%(43 / 225)$ of cases there was a failure upon the initial medical visit to make the correct diagnosis or to refer for further examinations which could have established the correct diagnosis. This caused delay of 2-5 months, (average 3.5), in the establishment of the diagnosis.

All of the cases of carcinoma of the oesophagus and $98 \%$ of the cases of carcinoma of the gastric cardia were suspected upon the X-ray contrast studies, no significant difference existing in this respect. Oesophagoscopy lead to the correct diagnosis in all but 3 patients, the correct diagnosis being established later upon operation.

\section{Discussion}

The distribution of the tumours by location in our patients corresponds well to previous reports (Stranahan et al., 1954; Lee, Thompson and De Luccia, 1967; Bateson, 1969), although there was relatively less carcinoma of the gastric cardia than reported by Appelqvist (1972).

Dysphagia and pain were present in our patients in approximately the same degree as reported by Appelqvist (1972). Respiratory symptoms were less commonly reported, which can be explained in part by the fact that there were relatively few cases of carcinoma of the upper part of the oesophagus in which these symptoms are prominent (Appelqvist, 1972). Loss of weight, vomiting, pain and other systemic symptoms are more common in carcinoma of the lower oesophagus and gastric cardia. Gastrointestinal bleeding occurred less frequently in this material than in that reported by Appelqvist (1972), as carcinoma of the cardia which bleeds was relatively less common in our material. The symptoms reported by our patients corresponded well to those reported by Inberg et al. (1974) in terms of dysphagia and weight loss, and to those reported by Stranahan et al. (1954) in terms of dysphagia, pain and bleeding.

There were no significant differences in the duration of symptoms before medical attention waso sought and the time needed for the establishment of the diagnosis when compared to the corresponding times reported earlier from Finland (Appelqvist, 1972; Inberg et al., 1974). This shows that the great distances which patients must travel in seeking medical attention, the sparse population and limited number of treatment facilities in northern Finland have not significantly influenced the figures. Lee et al. (1967) reported that patients with a tumour in the upper part of the oesophagus, and Appelqvist (1972) that patients with dysphagia, both seek medical attention more quickly than patients with other symptoms. Stranahan es al. (1954) and Neset (1967) reported that their patients sought medical attention on average 5-6 months after the onset of symptoms, our results thus being better in this respect.

The delay between the first visit at the doctor's office and the establishment of the diagnosis was of the same degree as that reported by Appelqvist (1972). He also reported that in as many as $45 \%$ of his patients there was a failure to refer for further study or to make the correct diagnosis upon the first medical contact, which resulted in a delay of 19 weeks before diagnosis in these patients. Our corresponding value of $19 \%$ is much more reassuring, but the reason for this difference cannoi fully be explained. There was no difference in the duration of symptoms. Long delays of over half a vear, or even a year, 
between the initial medical contact and the establishment of the diagnosis did not occur amongst our patients.

X-ray examination resulted in either the correct diagnosis or suspicion of malignancy more often than reported by Appelqvist (1972); this could be due to the development in radiological techniques over the decade.

Sufficient knowledge of the symptoms of carcinoma of the oesophagus and cardia and an active role on the part of the physician in searching for the diagnosis as well as education of the public to seek early medical attention, would all help in achieving more rapid diagnosis of these diseases and might thus improve the results of treatment. Contrast $\mathrm{X}$-ray studies, endoscopy and histological and/or cytological specimens, taken in conjunction with endoscopy, are the diagnostic tools of choice. Due to the only slight inconvenience of X-ray examination to the patient we recommend it as the primary examination in patients in whom carcinoma of the oesophagus is suspected. Endoscopy should be performed without hesitation in patients in whom there is a positive $\mathrm{X}$-ray finding and in patients in whom the X-ray diagnosis is not sufficient to explain the patients' symptoms. Lately, fiberoscopic endoscopy has often taken the place of radiological examinations as the primary diagnostic tool in diseases of the stomach (Salaspuro, 1980).

\section{References}

APPELQVist, P. (1972) Carcinoma of the esophagus and gastric cardia. A retrospective study based on statistical and clinical material from Finland. (Thesis). Acta chirurgica Scandinavica, 430 (Suppl.) 1.

Bateson, E.M. (1969) Carcinoma of the esophagus. Comparison of two radiological series from Jamaica and Western Australia. Australasian Radiology, 13, 345.

Borgeskov, S., Egedorf, J. \& Kruse-Blinkenberg, $\mathrm{H}$. (1976) Progress in esophagoscopy. Acta oto-laryngologica (Stockh), 82, 151.

Dietrich, R.A., Dockerty, M.B., Olsen, A.M. \& Ellis Jr, F.H. (1964) Clinicopathologic study of carcinoma involving the esophagogastric junction. Surgery, Gynecology and Obstetrics, 118, 1223.

Hegeman, G. \& Geldmacher, J. (1962) Zur Diagnose, Indikation und Behandlung des Ösophaguskarzinom. Zentralblatt der Chirurgie, 15, 621.

Inberg, M.V., Scheinin, T.M., Voutilainen, A., Havia, T. \& NikKanEN, T.A.V. (1974) Management of esophageal carcinoma. A report of 267 cases. Scandinavian Journal of Thoracic and Cardiovascular Surgery, 8, 220.

Lee, B.Y., Thompson, S.A. \& De Luccia, V.C. (1967) Carcinoma of the esophagus. A thirteen year study. International Surgery, 47, 84.

LE Roux, B.T. (1961) An analysis of 700 cases of carcinoma of the hypopharynx, the esophagus and the proximal stomach. Thorax, 16, 226.

NeSET, G. (1967) Tumor oesophagi. Tidsskrift for den Norske Laegeforening, 87, 806.

SAlaSPURo, M. (1980) Ulkustaudin muuttuva diagnostiikka. Duodecim, 20, 135.

Segi, M., Kurihama, M. \& Matsuyama, T. (1969) Cancer mortality for selected sites in 24 countries. Department of Public Health, Tohoku Univ. School of Medicine, Sendai, Japan.

Stranahan, A., Gobbel, W.G. \& Olson, K.B. (1954) Carcinoma of the esophagus. New York State Journal of Medicine, 54, 519.

Watson, W.L. (1933) Carcinoma of the esophagus. Surgery, Gynecology and Obstetrics, 56, 884. 